\title{
Trajetórias Afetadas de uma Cidade Corpo
}

\section{Afected Trajectories of a Body City}

ANDRADE, Francisco; Mestrando em Design; Universidade Federal de Pernambuco

franz.andraden@gmail.com

FIDELIS, Paulo; Mestrando em Design; Universidade Federal de Pernambuco

fidelispaulao@gmail.com

\section{Resumo}

Este artigo é o resultado de experimentos que envolvem a vivência corporificada da cidade do Recife através da errância ou deriva, percebida também como processo criativo dramatúrgico. 0 objetivo principal do projeto "Trajetórias afetadas de uma cidade corpo" é a produção artística inspirada nas diversas cidades que é o Recife, e a tradução das sensações, emoções e memórias afetivas em obra de arte. Ao analisar o projeto sob os pontos de vistas de diferentes teóricos urbanistas, das artes visuais, e performativas, reforça-se o valor da deriva como experiência corpórea e performativa do meio urbano, além de destacá-la como processo de criação artística enquanto dramaturgia.

Palavras Chave: cidade; corpo; deriva; processo criativo; dramaturgia.

\section{Abstract}

This article is the result of experiments involving the embodied experience of the Recife city through errance or dérive, which are perceived as well as a dramaturgical creative process. The main goal of the project "Affected trajectories of a body-city" is the artistic production inspired by the many cities within Recife city and the translation of the sensations, emotions and affective memories into an art piece. Analyzing this project using theories by different authors from urbanism, visual arts, and performing arts helps to reinforce the value of dérive as an embodied and performatic experience of the urban environment. Furthermore, the analysis highlights the dérive as a mean for artistic creation as dramaturgy.

Keywords: city; body; derive; creative process; dramaturgy. 


\section{Breve Discurso sobre a Cidade: o Olhar como Labirinto}

"Que é a cidade? Que processos promove? Que funções desempenha? Que finalidade preenche?" (MUNFORD, 1982, p. 9) questiona Lewis Munford no início de um de seus livros. A cidade é a grande sedutora e moradia do mundo moderno, seu imaginário é atraente. Todo o imaginário que se cria, em torno da cidade, ultrapassa a concretude das suas arquiteturas e invade a dimensão afetiva, muitas vezes escondida e desprezada, dando possibilidade a reconstrução do seu cotidiano. Seus espaços são como espelhos inquietos, precisam ser exaustivamente interpretados para analisarmos os muitos sentidos que eles acolhem, abertos a constantes significações (REZENDE, 2008).

Não se pode esquecer que a cidade possui um espaço incomensurável por onde o simbólico se institui e constitui, "é o humor de quem a olha que dá a forma à cidade" (CALVINO, 1990, p. 64). Seus habitantes constroem imaginários que não se limitam ao presente que vivem, não se consegue esgotar seus mistérios. Não existe, portanto, a cidade, mas, sim, cidades. Em As Cidades Invisíveis, Italo Calvino discursa sobre o olhar da cidade a partir de uma perspectiva mais ampla:

“[...]É uma cidade igual a um sonho: tudo o que pode ser imaginado pode ser sonhado, mas mesmo o mais inesperado dos sonhos é um quebra-cabeça que esconde um desejo, ou então o seu oposto, um medo. As cidades, como os sonhos, são construídas por desejos e medos, ainda que o fio condutor de seu discurso seja secreto, que as suas regras sejam absurdas, as suas perspectivas enganosas, e que todas as coisas escondam uma outra coisa.

$[\ldots]$

As cidades também acreditam ser obra da mente ou do acaso, mas nem um nem o outro bastam para sustentar as suas muralhas. De uma cidade, não aproveitamos as suas sete ou setenta e sete maravilhas, mas a resposta que dá às nossas perguntas."

(1990, p.44)

Com toda a confusão urbana, as cidades continuam simbolizando campos de liberdade e sensibilidade. Para Calvino, a cidade oferece surpresas para os olhos em todos os seus pontos (1990). Os cenários urbanos são inesgotáveis, dão forma aos desejos e materializam projetos, mas exige um olhar penetrante e atento para fazer outras leituras.

As formas das cidades multiplicam-se a partir dos olhares de seus habitantes, dos seus desejos e desesperos, um verdadeiro labirinto de possibilidades aparentemente desconexas, mas representativas da abstração das relações ocorridas entre metrópole, monumento e corpo. A cidade mantém um diálogo com o fabuloso, o metafórico e o simbólico, possibilitando uma outra forma de compreender as tramas humanas. Uma cidade são muitas cidades e é preciso interpretar esses contrapontos aproximando-se de outras linguagens possíveis, pois a cidade refaz a si própria todos os dias.

\section{Errâncias Urbanas: a Deriva como Experiência Corporal da Cidade}

Os errantes veêm a cidade como campo de investigações artísticas aberto a novas possibilidades sensíveis, e, assim, fornecem outras maneiras de analisar e estudar o espaço urbano através de suas obras ou experiências (JACQUES, 2004). As errâncias urbanas - ou a experiência corporal da cidade - permitem novos agenciamentos dos transeuntes, em que é possível apreender o espaço urbano de outra forma, partindo do pressuposto de que os errantes 
questionam de forma crítica a construção dos espaços. O simples ato de andar pela cidade permite levantar questionamentos de forma crítica sobre o urbanismo enquanto disciplina prática de intervenção das cidades (Idem, 2004).

Os novos espaços urbanos, cada vez mais privatizados ou não apropriados pela sociedade civil, nos levam a repensar as relações entre as paisagens urbanas e o corpo. O que se percebe é uma diminuição tanto da participação quanto da própria experiência corporal das cidades enquanto prática cotidiana, estética ou artística no mundo contemporâneo, a simples falha na experiência corporal do cotidiano. Os espaços urbanos se tornam simples cenários, sem corpo, espaços desencarnados (JACQUES, 2004).

As relações entre corpo e cidade podem mostrar alguns desvios, caminhos alternativos, linhas de fuga, ações de resistência ao processo que Guy Debord chamou de espetacularização das cidades contemporâneas (DEBORD in JACQUES, 2003). A cidade ganha corpo e é lida por ele a partir do momento em que ela é praticada, se torna um outro corpo, e cada corpo pode acumular diferentes corpografias, resultado das mais diversas experiências urbanas vividas. Para Jacques, a corpografia é uma cartografia corporal, parte da hipótese de que a experiência urbana fica inscrita, em diversas escalas de temporalidade, no próprio corpo daquele que experimenta (2008).

Cada corpo pode acumular diferentes corpografias, é necessário apreender os espaços urbanos para posteriormente propor outras formas de intervenção nas cidades. A deriva, proposta pela Internacional Situacionista, cujo pensamento foi encabeçado por Guy Debord, seria uma apropriação do espaço urbano pelo passante através da ação de andar sem rumo, uma alternativa de ação diante dessa espetacularização contemporânea. Preliminarmente, é necessário entender que a deriva seria a prática da psicogeografia que é a observação ativa das aglomerações urbanas de hoje e de formulação de hipóteses sobre a estrutura de uma cidade ou mesmo "o estudo dos efeitos exatos do meio geográfico, conscientemente planejado ou não, que agem diretamente sobre o comportamento afetivo dos indivíduos" (JACQUES, 2003, p. 22 ).

As grandes cidades são favoráveis à distração que chamamos de deriva, ela se mistura à influência do cenário. Os praticantes da cidade, como os errantes, realmente experimentam os espaços quando os percorrem e, assim, lhe dão "corpo" pela simples ação de percorrê-los, a cidade deixa de ser um simples cenário no momento em que é vivida. Cria-se algo como uma coreografia urbana, um tipo de cartografia realizada pelo e no corpo, ou seja, a memória urbana inscrita no corpo, um registro ou grafia de sua própria experiência da cidade, algo que fica inscrito, mas também configura o corpo de quem o experimenta.

"Ora, a rua é muito mais do que isso, a rua é um fator de vida das cidades, a rua tem alma", afirma João do Rio acerca de suas errâncias pela cidade (JACQUES, 2004) . Os errantes, ao usarem a deriva como forma de experiência vivida, atualizam os projetos urbanos e o próprio urbanismo através da prática, vivência ou experiência dos espaços urbanos. São essas experiências do espaço pelos habitantes, passantes ou errantes que reinventam os espaços no seu cotidiano, criando novas formas de labirinto, novos meios de apropriação da cidade utilizando o corpo como forma de resistência.

\section{A Deriva enquanto Processo Artístico Dramatúrgico}

Somando-se ao conceito de cidade enquanto espaço de múltiplos imaginários e da errância 
enquanto processo de experimentação artística nos meios urbanos, é interessante refletir sobre o processo aqui utilizado enquanto trabalho performático. Essa então seria uma perfórmance de tradução da experiência criativa, de tecer uma rede através da costura de seus elementos, em que tudo se concretiza no próprio fazer do trabalho.

Em seu livro Gesto Inacabado (1998), Cecília Almeida Salles defende que o ato criador é uma ação transformadora e de reorganização do mundo, capaz de criar novas conexões. Para ela, "A originalidade da construção encontra-se na unicidade da transformação: as combinações são singulares" (SALLES, 1998, P.89). Assim sendo, o processo artístico teria dois momentos transformadores principais, 1) o da percepção artística e a 2) escolha de recursos artísticos. Num primeiro momento, o artista age como explorador da existência, fazendo recortes, enquadramentos, e angulações, de acordo com o seu olhar único e transformador dos objetos. Já o segundo momento se relaciona mais como um movimento tradutório, afirma a autora. É nesse momento que ocorrem os experimentos, os testes, a escolha de qual material usar, e as justaposições. Por conseguinte, o processo experimental seria também um processo de conhecimento. Para Salles: "A criação é sob esse ponto de vista, conhecimento obtido por meio da ação" (Idem, 1998., p. 122), ou seja, é no fazer que o artista conhece o mundo, sua matéria, seu trabalho e a si mesmo. Subentende-se, então, que a tessitura dos vínculos citada por Cecília ocorre dessa maneira, não premeditada - pelo menos não totalmente - no próprio decorrer do ato criador.

A autora fala um pouco mais sobre essa tessitura em seu livro Redes de Criação Construção da obra de arte (2008), caracterizando o processo criativo enquanto rede interativa, dinâmica, e relacional. É por essa rede que se dá a obra de arte e sua definição: "é interessante pensar que a rede da criação se define em seu próprio processo de expansão: são as relações que vão sendo estabelecidas, durante o processo, que constituem a obra" (SALLES, 2008, p.32). Do ponto de vista de Cecília, a obra de arte seria fruto de um processo contínuo e inacabado de ligação de pontos, e a criação de relações tradutoras do mundo com a percepção do artista, tradução essa que ocorre com a construção do conhecimento durante o ato do fazer. Nesse contexto, é possível relacionar o processo artístico descrito por Salles com os conceitos de dramaturgia trazidos por Matteo Bonfitto e André Lepecki

Matteo Bonfitto também constrói a ideia de uma rede, dessa vez aplicada ao teatro. Em seu artigo "Tecendo os sentidos: a dramaturgia como textura", publicado na revista Pitágoras 500 em 2011, o autor cita a importante contribuição dos dramaturgos Brecht e Artaud, que, apesar de possuírem algumas dissonâncias teóricas, assemelhavam-se ao considerar a dramaturgia para além do texto escrito, sendo ela a articulação dos elementos cênicos (BONFITTO, 2011.). Mais adiante em seu texto, Bonfitto afirma que a dramaturgia seria a "operação através da qual elementos cênicos não convergem para um mesmo ponto, mas são entrelaçados de maneiras diversas, são 'tecidos'” (BONFITTO, 2011, P.58). Esse conceito se aproxima bastante do conceito de redes de criação de Cecília nos aspectos relacionais e interativos dos objetos e processos. Nesse sentido, pode-se enxergar o processo de criação artística trazida pela autora como também a construção de uma dramaturgia da obra, do artista enquanto perfomer. Essa ideia é ainda reforçada pela colocação de Bonfitto de que o conceito de dramaturgia tem-se ampliado consideravelmente, e que a "noção de 'dramaturgia como textura' pode ser relacionada ao trabalho do performer, que, como já observado, é frequentemente dissociado da representação e da ficcionalização" (Idem, 2011, p.60). 


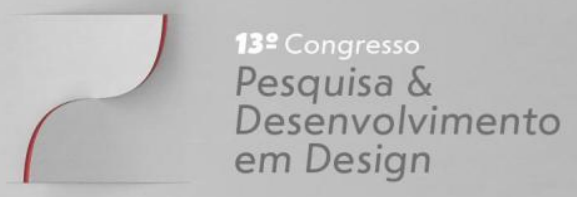

Artigo Completo

Retratando a figura do artista enquanto performer, a dramaturgia seria então processual, tema que dialoga com as ideias de André Lepecki apresentadas no texto Errância como trabalho: sete notas dispersas sobre dramaturgia da dança do livro Dança e Dramaturgias (2016). Nele, o autor, além de posicionar a dramaturgia no lugar do processo de criação, indica que o principal problema dessa dramaturgia na dança seria do "saber", e que seu papel enquanto trabalho de interação diária seria o de "ser um incansável e metodológico exercício de destruição da figura do que é o suposto 'saber"' (LEPECKI, 2016., P.65). Para tanto, Lepecki sugere que o dramaturgista, aqui considerado como a figura do artista visual, exercite a errância no sentido de "derivar, perder-se, extraviar-se" (Idem, 2016, P. 67). Sendo assim, é possível concluir que existe uma concordância entre os estudos de Salles e Lepecki, no sentido de que o conhecimento se dá no ato do fazer e trabalhar. Para o Lepecki:

A dramaturgia como prática dá ocasião à descoberta de que é o trabalho em si que estabelece sua própria soberania, seus próprios desejos e comandos performativos. A dramaturgia como uma prática da errância descobre que é o trabalho-por-vir que detém sua própria força autoral. (2016, p.75)

Tomando então este projeto como um ato de criação dramatúrgica, percebe-se ainda mais a conexão entre esses conceitos ao se verificar as escolhas definidas ao longo do processo. 0 trabalho foi iniciado sem um objetivo realmente claro e definido do que viria a ser produzido, assumindo de fato esse lugar do não-saber. O que se tinha era apenas a vontade de explorar a cidade como campo de investigações artísticas, uma cidade-corpo, viva, com cenários moventes, dando lugar ao simbólico e seus mistérios, abrindo espaço para novas possibilidades de observação e performatividades.

A experiência urbana cotidiana pode se dar de maneiras bem diferentes. A deriva defendida por Debord e mencionada por Lepecki em seus textos, foi a melhor alternativa encontrada para este projeto, aproximando, assim, ainda mais o fazer artístico com os conceitos citados anteriormente. É evidente a construção de uma dramaturgia durante o percurso, uma conexão dos elementos relativos tanto às subjetividades individuais quanto ao material coletado. A título de comparação, essas conexões foram feitas de fato no ato do fazer criativo, da exploração, a fim de (re) construir e analisar nossas próprias corpografias, utilizando o corpo enquanto resistência aos cenários urbanos atuais e assim trazer uma maior nitidez das formas simbólicas da cidade.

\section{O Experimento: Cidade, Memória e Afetividade}

Todas as cidades são geológicas, e não é possível dar dois passos sem de fato esbarrar em fantasmas cercados de todo prestígio lendário. Vivemos numa paisagem fechada cujos pontos de referência remetem sempre ao passado, pré-existências corporais resultantes da experiência do espaço (JACQUES, 2008). Michel de Certeau, em seu livro A Invenção do cotidiano, nos fala daqueles que experimentam a cidade, que vivenciam de dentro. Os errantes seriam esses vivenciadores que experimentam o espaço urbano através dessa ação de andar sem rumo. A deriva contém esse deixar-se levar.

O importante no experimento era a definição de uma cartografia afetiva que aflorasse a medida em que se era exposto a passagem rápida por ambiências variadas da centro da cidade do Recife, burlando as barreiras tradicionais do território urbano. $O$ interesse era vivenciar aqueles caminhos de forma diferenciada da qual estávamos acostumados. Sendo assim, optou-se por 
também inserir o experimento em um processo artístico mais amplo e fornecedor de material tangível e multimídia, se utilizando do registro de nossas memórias através de fotografias, vídeos e ilustrações. Decidiu-se exercitar esse processo de deriva inicialmente em dois momentos.

\section{Momento I}

O projeto se inicia com o encontro na Av. Guararapes, no centro da cidade do Recife. Até então não havia sido decidido de fato um ponto inicial para o início de nossa jornada pautada na deriva, nos deixando levar desde o princípio. Os motivos da escolha desse lugar foram a sua facilidade de acesso e o interesse por seus arredores. Seguiu-se para a Rua da Aurora, com o intuito de ali utilizar um ônibus aleatório e vagar pela cidade de forma indefinida. É importante ressaltar que nesse momento houve uma mudança de planejamento, uma vez que a intenção inicial era a de perder-se utilizando algum transporte público motorizado e posteriormente andar a esmo pela cidade. Entretanto esse tipo de ação pareceu não ser necessário. Houve o entendimento de que apenas caminhar pelas redondezas faria mais sentido, a fim de vivenciarmos uma experiência afetiva diferenciada com o espaço urbano, permitindo novas formas de agenciamento da cidade. Continua assim nossa errância enquanto performance.

Chega-se então na R. Princesa Isabel, perto do Parque 13 de Maio, deixando-se levar de fato somente pelo impulso. Porém, neste ponto, há uma mudança de configuração mental e decide-se pela primeira vez algum tipo de destino, a Rua Capitão Lima (figura 1), lugar de muitas memórias e afetos vivenciados no passado. Assim, inicia-se nossa busca de locais afetivos da cidade do Recife, revisitando memórias e experiências do passado. Na Rua Capitão Lima, ocorreram festas de universidades, encontros de dança, contato e improvisação, almoço com amigos e até mesmo uma tentativa de assalto. Importante citar que ao longo de todo o percurso foram feitos diversos vídeos e fotografias que pudessem registrar essa nova travessia pelos lugares que de uma forma ou outra marcaram nossas memórias.

Figura 1 - Rua Capitão Lima, Recife - PE

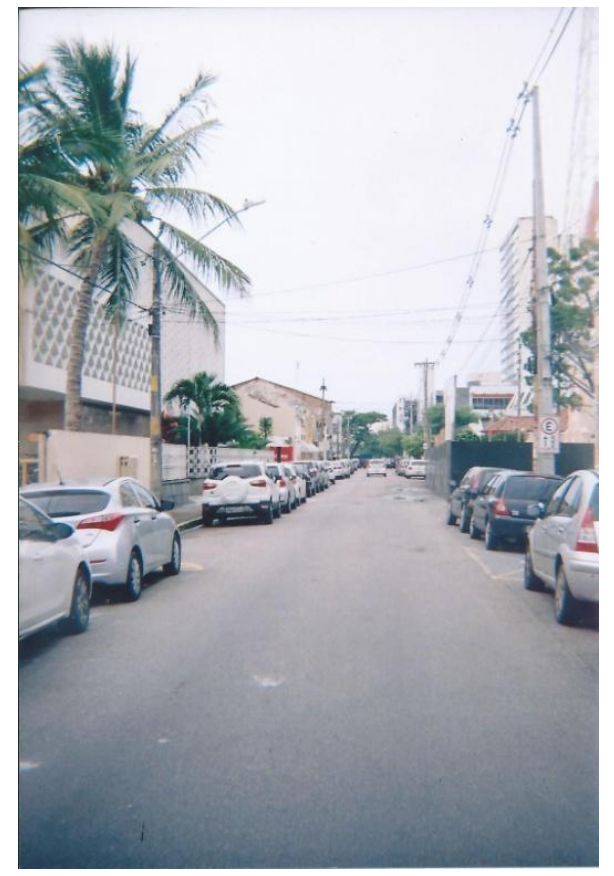

Fonte: do autor 
Continuando o percurso, entra-se na R. do Pombal, desbocando na Av. Visconde de Suassuna, a "avenida dos médicos" bastante frequentados na juventude. Nossas vivências foram construídas a partir do momento em que passávamos em determinados locais, reavivando experiências, que por vezes não se revelaram muito boas para os autores deste artigo.

O próximo ponto do itinerário fora então a R. Afonso Pena, pois de alguma forma era atraente. Talvez faça sentido de fato uma rua bastante arborizada como a Afonso Pena, chamar atenção numa cidade como Recife, que não é das mais amigáveis para com a natureza. Passou-se rapidamente pela R. do Príncipe, pela R. Nunes Machado, e a R. da Soledade é escolhida para ser experienciada como marco de memória, lugar de experiência curiosa: um dos prédios dali já foi cenário de um encontro sexual casual marcante para um dos vivenciadores. Como disse, nem todos os pontos de passagem foram marcados por momentos de felicidade.

Andamos pela R. do Riachuelo, entrando na rua do Teatro Valdemar de Oliveira, visto constantemente de longe, pela janela de um carro na infância. O teatro possuía uma força magnética que de certa maneira atraía aquela criança no automóvel, porém o encontro entre o espaço e a criança, infelizmente, nunca se concretizou. Próxima parada: posto de gasolina do Select da Av. Conde da Boa Vista, ponto de encontro LGBTTQ+ de Recife, bastante familiar ambos.

Segue-se em frente pela rua do colégio Salesiano, e novamente a infância vem à tona através do jogos de vôlei pelo time da escola. Essas lembranças da escola persistem pelas ruas vizinhas do bairro da Boa Vista, pela rua da FAV, seguindo pela rua por trás do Colégio de São José, onde "Seu Bil" vendia uma coxinha e um refrigerante em lata por apenas $\mathrm{R} \$ 2,00$. O fim do percurso se deu no Shopping Boa Vista e um emaranhado de emoções se apresenta: festas de aniversários, encontros depois da aula, idas ao cinema, lugar de conversas e desabafos, espaço marcante de liberdade.

\section{Momento II}

A segunda deriva realizada foi um pouco mais curta que a primeira. Iniciamos o percurso na Praça do Derby, com uma maior consciência do que poderia acontecer. Ali, o que mais nos chamou a atenção foi a moradia improvisada dos habitantes locais da rua e seu varal-gradil de canteiro. A cidade também é local de desigualdades sociais e olhares desviados para a pobreza do outro. Da Praça do Derby partimos para o prédio da Fundação Joaquim Nabuco, era impossível ignorar um lugar de tantas descobertas e vivências cinematográficas da adolescência. A próxima parada foi a R. Henrique Dias, passando em frente ao hotel de mesmo nome, lugar de (des) encontros e satisfação de desejos (figura 2).

Fomos então à Av. Conde da Boa Vista, pela R. Dom Bosco, parando no posto de gasolina na esquina das duas ruas para comer. Ali ao lado algumas horas foram perdidas, esperando por vários projetos serem impressos pela Copyshop Copiadora. Torna-se ao Derby, em seguida a R. das Creoulas, lugar de rodízios de massa já bastante consumido entre amigos, entrando na R. das Pernambucanas e indo até a Academia Studio de Dança, onde finaliza-se nossa empreitada. 
Figura 2 - Registro da frente do Hotel Henrique Dias

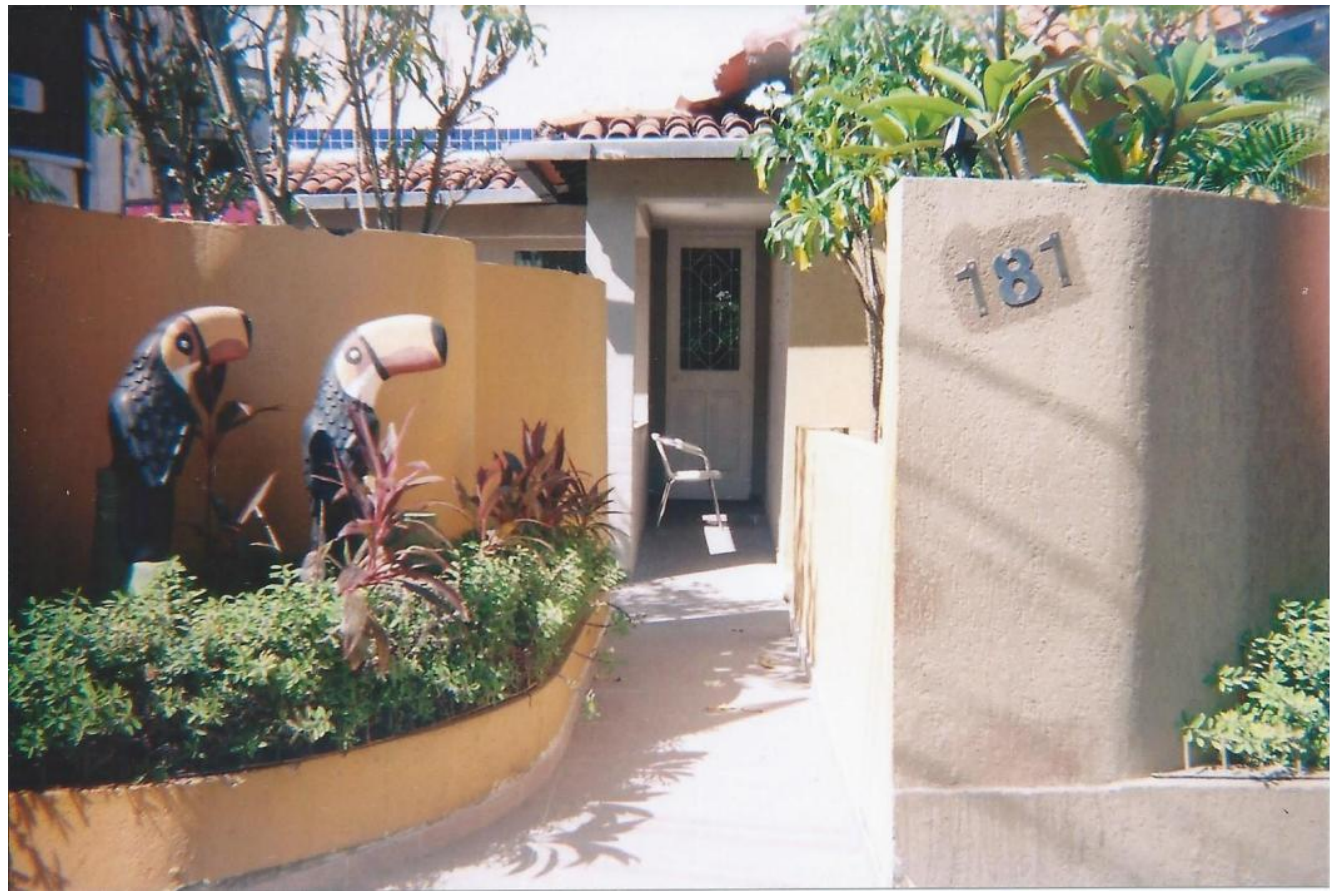

Fonte: do autor

\section{Considerações Finais}

Não é possível dizer o que é mais evidente na experimentação deste projeto de deriva da cidade do Recife, especialmente sob a luz dos conceitos aqui abordados. Tudo aparenta ser extremamente latente e de igual importância considerando ainda que este presente artigo é, indubitavelmente, um gesto inacabado. Durante o processo descrito neste artigo, ficou evidente para os autores que a concretude da cidade funciona como ponte de acesso a diversas formas de afeto que se cruzam ou se distanciam a cada nova rua ou avenida caminhada. Tudo ao redor apresenta potência de transferência ao imaginário quando assim se permite, como coloca Rezende.

A cada nova descoberta pessoal, sentiu-se a mudança na forma de estar no espaço urbano, inscritas no próprio corpo, como bem pontuou Jacques. Todas as memórias, afetos e descobertas compõem a percepção artística dos autores para a criação das primeiras obras, que aqui serão tratadas como rascunhos devido ao caráter inacabado deste projeto, os cenários das cidades são inesgotáveis. A tradução, para usar o termo de Salles, se baseia nessas cidades vivenciadas no decorrer das derivas realizadas pelos autores, registradas através das diversas mídias utilizadas no processo.

Importante ressaltar, também, que todas essas escolhas se deram no decorrer do processo, instigadas pela experiência corporificada da cidade. Sentiu-se assim uma proximidade com as teorias de Bonfitto e Lepecki, principalmente no tocante às filmagens realizadas durante todo o percurso. Ao se ter consciência da gravação dos movimentos, o aspecto performático do processo criativo é evidenciado, existiu uma consciência maior do que se dizia e da tessitura afetiva que se formava. 
Por fim, reafirma-se que todas essas latências relatadas se deram através da percepção de uma cidade múltipla e que se transforma, em conjunto com os corpos que a vivenciam. Memórias revividas e ressignificadas que guiam passos e sentimentos. Também é a memória que leva o artista a performar sua obra, construída lentamente a cada virar de esquina ou a cada lembrança pós trajeto. Uma obra mutante que carrega uma percepção subjetiva do sujeito. Tudo se concentra numa obra-performance-cidade, que, dialogando com a fala de Calvino em As Cidades Invisíveis, é como "teias de aranha de relações intrincadas à procura de uma forma" (1990, p. 72).

Figura 3 - Algum rascunho de uma cartografia afetiva. Colagem em papel Colorplus A3.

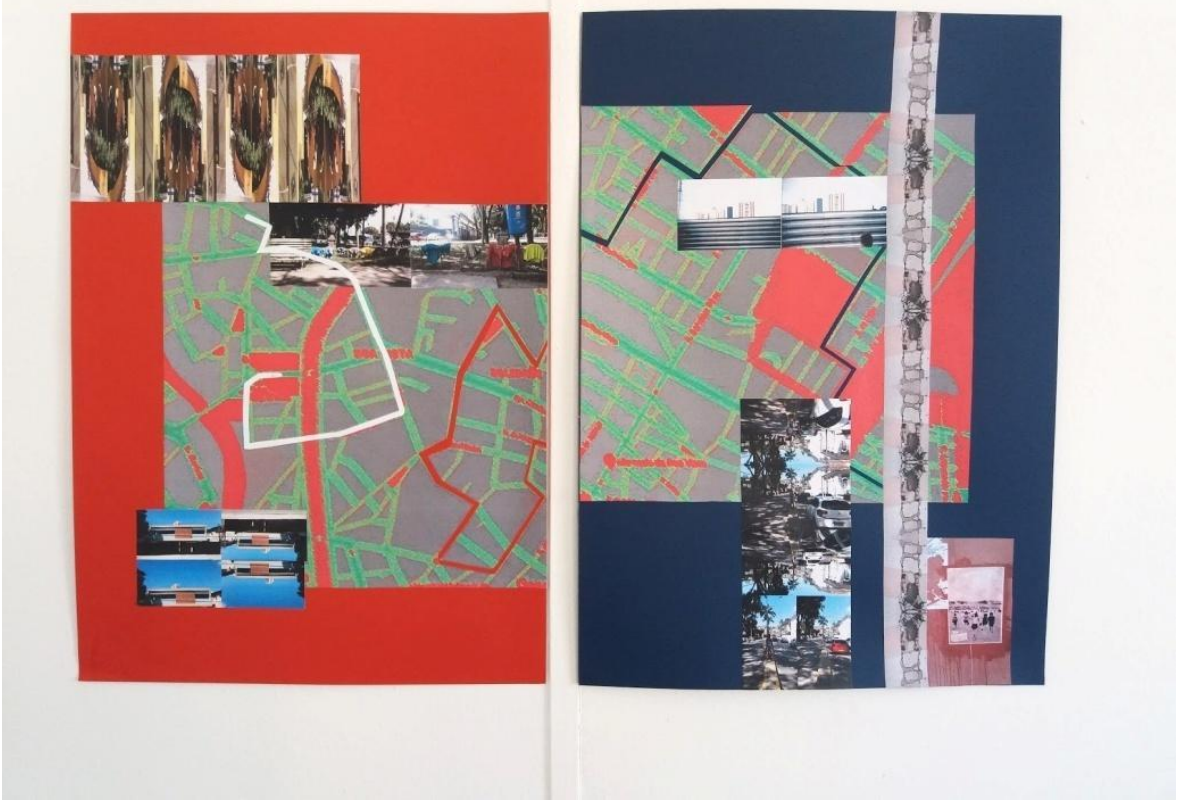

Fonte: do autor

\section{Referências}

BONFITTO, Matteo. Tecendo os sentidos: a dramaturgia como textura. Pitagoras, 500 v.1. Out 2011 p. 56.

CALVINO, Italo. As cidades invisíveis. São Paulo: Cia das Letras, 1990.

JACQUES, Paola Berenstein (Org.). Apologia da Deriva: escritos situacionistas sobre a cidade / Internacional Situacionista. Rio de Janeiro: Casa da Palavra, 2003.

. Corpografias urbanas. Arquitextos, São Paulo, ano 08, n. 093.07,

Vitruvius, fev. 2008 Disponível em:
http://www.vitruvius.com.br/revistas/read/arquitextos/08.093/165. Último acesso em 21 de novembro de 2017.

. Elogio aos errantes. Breve histórico das errâncias urbanas.

Arquitextos, São Paulo, ano 05, n. 053.04, Vitruvius, out. 2004. Disponível em 
http://www.vitruvius.com.br/revistas/read/arquitextos/05.053/536. Último acesso em 21 de novembro de 2017.

LEPECKI, André. Errância como trabalho: sete notas dispersas sobre dramaturgia da dança In Dança e Dramaturgias. Ed. $\mathrm{n}$ - 1, 2016.

MUNFORD, Lewis. A cidade na história: suas origens, transformações e perspectivas. Trad. de Neil R da Silva. São Paulo, Martins Fontes; Brasília, Editora da Universidade de Brasília. 1982.

REZENDE, Antonio Paulo. Cidade e Modernidade: Registros Históricos do Amor e da Solidão no Recife dos anos 1930 In História, cultura e sentimento: outras Histórias do Brasil / apresentado e organizado por Antonio Torres Montenegro... et al. - Co-edição - Recife: Ed. Universitária da UFPE; Cuiabá: Ed. da UFMT, p. 45-71, 2008.

O Recife: os espelhos do passado e os labirintos do presente ou as tentações da memória e as inscrições do desejo. (1999) Disponível em: https://revistas.pucsp.br/index.php/revph/article/view/10993/8113. Último acesso em 21 de novembro de 2017.

SALLES, Cecília Almeida. Gesto inacabado: processo de criação artística. Editora Annablume, 1998. PDF.

Redes da criação: construção da obra de arte. Editora Horizonte. 2008. 